\title{
Evaluación de la igualdad y no discriminación de pueblos indígenas en la jurisprudencia del Tribunal Constitucional peruano
}

\author{
Equality and non-discrimination assessment of indigenous peoples in \\ Peruvian Constitutional Court decisions
}

\author{
David LovaTón ${ }^{1}$ \\ Pontificia Universidad Católica del Perú (PUCP) \\ mlovaton@pucp.edu.pe
}

\begin{abstract}
Resumen: El presente artículo pasa revista al estado del arte del desarrollo contemporáneo, tanto doctrinal como jurisprudencial, del derecho fundamental a la igualdad y no discriminación de las personas y pueblos indígenas, con el propósito de identificar el contenido constitucional e interamericano de este derecho que el Tribunal Constitucional (TC) peruano podría tomar en cuenta. Luego, analiza la escasa jurisprudencia desarrollada por el TC en esta materia hasta el momento de escribir el presente documento para, finalmente, formular algunas recomendaciones al máximo intérprete de la Constitución en torno a cómo podría desarrollar a
\end{abstract}

1 Abogado, magister en derecho constitucional y doctor en derecho por la Pontificia Universidad Católica del Perú (PUCP). Profesor principal PUCP, Director del Centro de investigación, Capacitación y Asesoría Jurídica (CICAJ) de la PUCP y Consultor de la Fundación para el debido proceso (DPLF, por sus siglas en inglés). El autor hace parte del Grupo de Investigación en Derecho Constitucional y Derechos Fundamentales (GIDCYDEF-PUCP) y del Proyecto de investigación "Contribución de la jurisprudencia del Tribunal Constitucional a la afirmación del derecho a la igualdad y no discriminación para grupos en situación de especial vulnerabilidad en el Perú" que desarrolló dicho grupo de investigación, cuyos integrantes formularon valiosos aportes y comentarios al presente artículo.

Artículo recibido el 3.07.2020 y aprobado para publicación el 13.08.2020. 
futuro el derecho fundamental a la igualdad y no discriminación de las personas y pueblos indígenas, a partir de las nociones de discriminación estructural, indirecta e interseccional.

Palabras claves: Pueblos indígenas y originarios, discriminación estructural, discriminación interseccional.

\begin{abstract}
This article reviews the state of the art of contemporary development, both doctrinal and jurisprudential, of the fundamental right to equality and non-discrimination of indigenous people, with the purpose of identifying the constitutional and inter-American content of this right that the Peruvian Constitutional Court (TC) could take into account. Then, it analyzes the limited jurisprudence developed by the TC in this matter until the moment of writing this document. Finally, the article makes some recommendations to the high constitutional court of regarding how the fundamental right to equality of indigenous people could develop in the future, based on the notions of structural, indirect and intersectional discrimination.
\end{abstract}

Keywords: Indigenous and native peoples, structural discrimination, intersectional discrimination.

\title{
1. Introducción
}

El derecho fundamental a la igualdad y a la no discriminación ha merecido un amplio y prolijo desarrollo doctrinal y jurisprudencial, tanto en el derecho constitucional como en el derecho internacional de los derechos humanos, lo que ha favorecido a diversos sectores o grupos sociales históricamente discriminados, como mujeres, afrodescendientes o pueblos indígenas, tan sólo por mencionar algunos. También ha supuesto la pacífica aceptación de la igualdad no sólo como un derecho fundamental sino como un principio jurídico tanto del derecho nacional como del derecho internacional de los derechos humanos, al punto que 
ahora es considerada una regla jus cogen vinculada a la dignidad humana por la Comisión $^{2}$ y la Corte interamericanas. ${ }^{3}$

A la vez, lamentablemente también es consenso que los pueblos indígenas en América Latina y en el Perú han sido y son, uno de los sectores sociales que han sufrido históricamente discriminación, a partir de la conquista y colonización europea, lo que ha supuesto su empobrecimiento y una mayor vulnerabilidad estructural. Para hacer frente a ello, desde el campo jurídico se han ido reconociendo y desarrollando los derechos fundamentales de los pueblos indígenas, tanto en el ámbito individual, pero, sobre todo, en el ámbito colectivo. Esta noción de "derechos fundamentales" hunde sus raíces en el liberalismo surgido de las revoluciones francesa y norteamericana de finales del siglo XVIII y, por ende, un sector importante de las organizaciones indígenas y de la academia mantienen una comprensible desconfianza frente a una suerte de imperialismo cultural de Occidente. ${ }^{4}$

A la vez, hay otro sector importante -al que nos adscribimos- que postula reinterpretar estos derechos fundamentales en el marco de un constitucionalismo "multicultural contrahegemónico"s, lo que, entre otras cosas, significa que si bien

\footnotetext{
2 "Desde la más temprana jurisprudencia del sistema interamericano, se ha destacado sobre el principio de igualdad que esta noción se desprende directamente de la naturaleza humana y es inseparable de la dignidad esencial de la persona, razón por la cual es incompatible toda situación que, por considerar superior a un determinado grupo, conduzca a tratarlo con privilegio; o que, a la inversa, por considerarlo inferior, lo trate con hostilidad o de cualquier forma lo discrimine del goce de derechos que sí se reconocen a quienes no se consideran incursos en tal situación de inferioridad." CIDH (2019a), párrafo 4.

3 “(...) este Tribunal considera que el principio de igualdad ante la ley, igual protección ante la ley y no discriminación, pertenece al jus cogens, puesto que sobre él descansa todo el andamiaje jurídico del orden público nacional e internacional y es un principio fundamental que permea todo ordenamiento jurídico. Hoy día no se admite ningún acto jurídico que entre en conflicto con dicho principio fundamental, no se admiten tratos discriminatorios en perjuicio de ninguna persona, por motivos de género, raza, color, idioma, religión o convicción, opinión política o de otra índole, origen nacional, étnico o social, nacionalidad, edad, situación económica, patrimonio, estado civil, nacimiento o cualquier otra condición. Este principio (igualdad y no discriminación) forma parte del derecho internacional general. En la actual etapa de la evolución del derecho internacional, el principio fundamental de igualdad y no discriminación ha ingresado en el dominio del jus cogens." CORTE IDH (2003), p. 101.

4 “(...) en su concepción hegemónica, los derechos humanos son individualistas y culturalmente occidentocéntricos y, en esa medida, son más parte del problema que de la solución." Santos (2014), p. 19. Por ello, el mismo autor señala que si se pretende hacer un uso contrahegemónico de los derechos humanos, debe partirse de la sospecha de su matriz liberal y occidental: "La búsqueda de una concepción contrahegemónica de los derechos humanos debe comenzar con una hermenéutica de la sospecha respecto a estos derechos, tal y como se entienden y defienden de manera tradicional, es decir, en relación con las concepciones de los derechos humanos más directamente vinculadas a su matriz liberal y occidental (...)”. SANTOS (2014), p. 24.

5 RodrígueZ y BAQUero (2015), p. 21.
} 
es una noción de origen liberal y occidental, puede ser reinterpretada y utilizada a favor de los pueblos indígenas ${ }^{6}$ asumiendo, entre otros aspectos, que el "sujeto de derecho" no sólo es el individuo - que también lo es, por cierto- sino también un sujeto colectivo como la comunidad o el pueblo indígena o que la idea de "dignidad humana" -a la que la noción de "derechos fundamentales" está intensamente ligada-, también debe comprender otras cosmovisiones vinculadas a la Naturaleza o al territorio.

Pese a este prolijo desarrollo jurisprudencial y doctrinal en torno al principio/ derecho de igualdad y no discriminación por un lado y al amplio consenso en torno a que uno de los sectores sociales históricamente discriminados en Perú y América Latina ha sido y sigue siendo los pueblos indígenas por otro, aún ello no se ha traducido suficientemente en el desarrollo del derecho fundamental de igualdad y no discriminación referido a los pueblos indígenas en la jurisprudencia constitucional peruana.

Si bien el Tribunal Constitucional (TC) ha hecho aportes jurisprudenciales importantes a favor de algunos derechos fundamentales de los pueblos indígenas, como es el caso del derecho a la consulta previa, libre, informada y culturalmente adecuada, es aún insuficiente lo que ha construido en torno al derecho a la igualdad y no discriminación de los pueblos indígenas, si se le compara con la jurisprudencia de la Corte interamericana de derechos humanos, los informes de la Comisión interamericana de derechos humanos o los pronunciamientos de los diversos órganos del Sistema universal de derechos humanos, en un contexto contemporáneo de diálogo judicial entre las altas judicaturas nacionales y las cortes u órganos internacionales de derechos humanos y de internacionalización del derecho constitucional.

Por ello, el presente artículo pretende, por un lado, analizar la escasa jurisprudencia que a la fecha ha desarrollado el TC en esta materia y determinar lo avanzado y, por otro, identificar algunos temas aún por explorar y desarrollar a futuro por parte de nuestro máximo intérprete constitucional. En ese sentido, no abordamos otros derechos fundamentales de los pueblos indígenas que la doctrina y

6 “(...) Pero también es igual de necesario distinguir las concepciones hegemónicas de los derechos humanos -destinadas, a mi entender, a legitimar las ideologías de individualismo propietario y, en consecuencia, a reproducir el (des)orden social capitalista, colonialista y patriarcal que domina nuestro tiempo-, de las concepciones contrahegemónicas que ofrecen concepciones alternativas de autonomía potencialmente orientadas a la creación de una sociedad más justa y más digna." SANTOS (2014), p. 19. 
jurisprudencia han desarrollado, como la consulta previa, la libre determinación o la jurisdicción indígena.

Para tal efecto, partimos de la evolución y las diversas aproximaciones teóricas contemporáneas a la igualdad y no discriminación, presentando un estado del arte sobre el particular. Posteriormente, comentamos algunas de las nociones o definiciones contemporáneas de pueblo indígena en América Latina, con el propósito de identificar al sujeto de derecho indígena de la igualdad y no discriminación. Luego, desarrollamos lo que consideramos uno de los mayores retos que enfrentamos en Perú y América Latina en esta materia: la discriminación estructural, indirecta e interseccional que con frecuencia padecen los pueblos indígenas, que debería enfrentarse, principalmente, con acciones afirmativas a nivel colectivo. Al final, desarrollamos lo que ha avanzado la jurisprudencia del TC en esta materia y el trecho que aún le falta por construir en materia de estándares, técnicas y principios de interpretación constitucional.

Valoramos que el TC peruano haya hecho algunos aportes en torno al derecho/ principio de igualdad y no discriminación por un lado y respecto a los derechos fundamentales de los pueblos indígenas por otro, pero aún no ha desarrollado suficientemente el contenido contemporáneo de la igualdad y no discriminación en el ámbito de los derechos de los pueblos indígenas.

En ese sentido, consideramos que no se puede seguir combatiendo satisfactoriamente esta discriminación recurriendo tan sólo a las herramientas clásicas como el test de igualdad o la igualdad ante la ley que, sin duda, mantienen su vigencia para algunos casos. Es indispensable desarrollar nuevas herramientas jurídicas como tomar en cuenta el contexto histórico, social, económico o cultural de discriminación estructural, la adopción de acciones o medidas afirmativas, el seguimiento ex post de algunas de sus sentencias por parte de los altos tribunales nacionales e internacionales o de políticas públicas para equilibrar, en los hechos, la situación de desigualdad en la que se encuentran los pueblos indígenas.

$\mathrm{Al}$ respecto, es indispensable entender que, en el caso de los pueblos indígenas, la realización del derecho/principio de igualdad y no discriminación no pasa en Perú y América Latina principalmente por el trato igualitario no discriminatorio -aunque también-, sino sobre todo por un trato justificada y constitucionalmente desigual, propio de una sociedad democrática, tanto en el plano individual como colectivo, a favor de los pueblos indígenas. Resulta paradójico que, para que los pueblos indígenas gocen de un trato constitucionalmente igualitario, sea necesa- 
rio que sean constitucionalmente favorecidos con acciones positivas y políticas públicas dirigidas a combatir condiciones históricas y estructurales de vulnerabilidad. Ese es el horizonte que el presente artículo aspira a plantear a la jurisprudencia constitucional en el Perú.

\section{Evolución y aproximaciones teóricas contemporáneas a la igualdad y no discriminación}

En el presente acápite desarrollamos brevemente el actual estado del arte sobre la materia, tanto en el derecho constitucional como en el derecho internacional de los derechos humanos.

Para ello nos basaremos principalmente en los trabajos de la profesora Liliana Salomé, en autores como Roberto Saba y Claudio Nash, en el Compendio sobre igualdad y no discriminación publicado por la Comisión interamericana de derechos humanos, en los cuadernillos de jurisprudencia de la Corte interamericana de derechos humanos sobre igualdad y no discriminación y sobre derechos de pueblos indígenas y en la Observación General № 18 del Comité de derechos humanos de Naciones Unidas, entre otras fuentes bibliográficas.

La clásica definición de Aristóteles de la igualdad y no discriminación -que era lo que él entendía por justicia-, como "trato igual a los iguales y trato desigual a los desiguales", es un buen punto de partida que claramente hoy en día ha quedado superada. Esta idea original de la igualdad en el sentido que el trato diferenciado está permitido en tanto las personas no sean iguales, ha sido desarrollada, ampliada y superada en varios sentidos. En primer lugar, que hay tratos desiguales no permitidos por el derecho sino sólo aquellos que tengan un fin constitucional y convencionalmente válido, razonable y proporcional y, para determinar ello, se ha desarrollado el conocido test de igualdad. ${ }^{7}$

En segundo lugar, que hay desigualdades en los hechos que deben ser compensadas por el derecho por un tiempo, con el propósito de equilibrar parcialmente las posiciones de las partes en una relación o situación determinada; surgieron así nuevas ramas del derecho como el derecho laboral a favor del trabajador, la protección del consumidor o el interés superior del niño, entre otras. De esta manera, se incorpora al contenido constitucionalmente protegido del derecho de igualdad

7 Desarrollado por el Tribunal Constitucional (TC) peruano en el "caso Profa" (Sentencia del Tribunal Constitucional del Perú $\mathrm{N}^{\circ}$ 045-2004-PI, de 29 de octubre de 2005). 
y no discriminación, la igualdad sustancial, material o de oportunidades. ${ }^{8}$ Más adelante, esta igualdad de oportunidades será el ladrillo argumentativo para justificar e implementar acciones positivas y políticas públicas a favor de determinados sectores o grupos sociales.

En tercer lugar, la igualdad y no discriminación comienza a ser analizada no sólo en el ámbito de las relaciones individuales, sino también en relación a sectores o grupos sociales, esto es en el ámbito colectivo y de la sociedad en general, erigiéndose, así como un principio y pilar del Estado constitucional. De ahí la pacífica aceptación contemporánea de la igualdad y no discriminación no sólo como un derecho sino también como un principio, resaltando su doble carácter tanto individual como colectivo o social.

En cuarto lugar y más recientemente, el contenido del derecho fundamental a la igualdad y no discriminación se interpreta tomando en cuenta los contextos sociales, económicos, culturales o políticos que pueden afectar gravemente este derecho en relación a determinadas personas o grupos sociales, que en los hechos se encuentran sometidos a condiciones de sometimiento de diverso cuño (económico, social, cultural, entre otros).

Surge así la idea de una discriminación de carácter estructural, ${ }^{9}$ en la que los grupos sociales desventajados se encuentran en una situación histórica y estructural de "subordinación" en relación a otros grupos sociales y, por ende, la discriminación no depende necesariamente de la voluntad de los individuos sino de estereotipos, prejuicios, prácticas culturales o estructuras sociales o económicas y que, frente a ello, es necesario que el derecho también responda con medidas o acciones positivas y sostenidas políticas públicas de favorecimiento de determi-

8 "(...) la igualdad material (también denominada "sustantiva" o "real") busca poner de manifiesto que, en la realidad, no todas las personas se encuentran en la misma situación (...). Esta manera de entender la igualdad ha dado lugar a que se incorporen nociones como la de igualdad de oportunidades (...)". SALOmé (2017), p. 14 .

9 “(...) se tomarán en cuenta aquellas propuestas que desde la doctrina se han elaborado en torno a la idea de "desigualdad estructural". Es el caso de Roberto Saba, quien reconstruye la noción usualmente aceptada de igualdad (entendida como trato no arbitrario) para capturar en ella los problemas de desigualdad estructural que enfrentan determinados grupos sociales. El autor parte del reconocimiento de la existencia de normas y prácticas sociales que posicionan a ciertos grupos en una situación de desventaja; $y$, en respuesta, propone una noción de igualdad que se caracteriza por incorporar una exigencia dirigida al desmantelamiento de situaciones de subordinación. En ese sentido, Roberto Saba articula su propuesta asociando la noción de igualdad con el principio de no sometimiento (...). Tanto Roberto Saba como Neus Torbisco se remiten en sus escritos al pensamiento del autor norteamericano Owen Fiss (...) principalmente, en relación con aquello que él denomina el "principio de apoyo a los grupos desaventajados". SALOMÉ (2017), pp. 50-51. 
nados sectores o grupos sociales, para contribuir a emanciparlos de esa situación de subordinación. ${ }^{10}$

Vinculado a lo anterior también está la idea de la discriminación indirecta en contraste con la discriminación directa; mientras ésta última supone el reto legal de probar en un caso concreto que hay el propósito o intención de discriminar indebidamente a una persona en comparación con otras, en cambio la discriminación indirecta parte del supuesto que una persona o grupo social puede sufrir algún tipo de discriminación por una medida o acción en principio neutral y sin intención de discriminarlos, pero que en los hechos genera un situación discriminatoria. ${ }^{11}$

Así, en la discriminación indirecta no será indispensable probar la intención discriminatoria, sino que bastará probar que una persona o grupo social se encuentra en una posición disminuida y discriminada objetivamente, en comparación con otras personas o grupos sociales que se encuentran -en un contexto histórico determinado- en una clara posición de privilegio. ${ }^{12}$

Finalmente, el derecho a la igualdad y no discriminación también ha visto ampliado su contenido constitucionalmente protegido con el aporte del movimiento feminista negro de los Estados Unidos en las décadas de los setenta y ochenta del siglo XX:13 la idea que una misma persona o grupo social puede padecer no sólo

$10 \mathrm{Al}$ respecto, $\mathrm{SABA}$ (2016), p. 81, sostiene: “(...) la noción de igualdad entendida como no sometimiento impacta sobre el modo en que concebimos y entendemos otros derechos reconocidos en las Constituciones y los tratados internacionales (...). Esta visión de la igualdad también operaría como guía para el diseño de políticas públicas que, por un lado, no deberían contribuir a perpetuar la situación de subordinación de grupos y, por el otro, deberían tender a desmantelar las estructuras sociales que producen esa subordinación (...)”.

11 "(...) la discriminación puede ser "directa" o "indirecta". La primera se verifica en aquellos casos en que la acción u omisión tiene por objeto el menoscabo en el goce de derechos de una o más personas, es decir, se realiza con el propósito o la intención de ocasionar ese perjuicio. En cambio, la denominada discriminación indirecta es aquella que sin perseguirlo ocasiona el mismo resultado, puesto que produce igualmente dicho efecto perjudicial. En términos más precisos, se ha estimado que la discriminación indirecta tiene lugar cuando una norma o medida en apariencia neutral produce un efecto perjudicial que impacta de manera exclusiva o desproporcionada sobre personas que forman parte de un grupo determinado, sin que dicha medida pueda justificarse de manera objetiva y razonable." NASH y DAVID (2010), p. 172.

12 NASH y David (2010), p. 72.

13 "Históricamente, suele atribuirse al Combahee River Collective el interés por las denominadas «opresiones múltiples y simultáneas» (manifold and simultaneous oppressions), expresión que es utilizada en su texto titulado «Un manifiesto feminista negro» (A Black Feminist Statement) publicado por primera vez en los Estados Unidos de América en el año 1977 (...) la preocupación en torno a la discriminación múltiple se ha debatido ampliamente bajo el término «interseccionalidad», acuñado en el ámbito académico a finales de los años ochenta, específicamente desde el estudio del Derecho, por la profesora norteamericana Kimberlé Williams Crenshaw. Los textos de esta autora han constituido, casi invariablemente, el punto de partida para contextualizar el inicio de esta discusión." SALOMÉ (2015), pp. 313-314. 
una sino varias y simultáneas discriminaciones, como calles que se pueden encontrar o intersectar en una esquina determinada. ${ }^{14}$ Surge así la noción de la discriminación "interseccional" o "múltiple"15 que una misma persona puede padecer por su condición de mujer, afrodescendiente y pobre, lo que sin duda agrava los efectos nocivos de tal discriminación múltiple y simultánea y, nuevamente, ante ello, el derecho debe construir respuestas legales novedosas para solucionar tal situación.

Como puede apreciarse de este rápido recuento de la evolución y ensanchamiento del contenido constitucionalmente protegido del derecho/principio de igualdad y no discriminación, el mismo es interpretado de forma extensa y abarca no sólo situaciones individuales sino también colectivas, ${ }^{16}$ toma en cuenta el contexto social, económico, político o cultural en un momento histórico determinado, contempla la posibilidad que la discriminación se produzca objetivamente sin la necesidad que haya la intención de hacerlo y, finalmente, es probable que una persona o grupo social se vea sometido a una múltiple y simultánea discriminación.

En medio de este amplio desarrollo y evolución del derecho/principio de igualdad y no discriminación, una de las definiciones más recurridas de este derecho es la que postula la Observación General No 18 del Comité de derechos humanos de Naciones Unidas adoptada en $1989 .{ }^{17}$

14 "La discriminación, como el tráfico en una intersección de calles, puede fluir en una y otra dirección. $\mathrm{Si}$ un accidente se produce en la intersección, este puede ser causado por automóviles que provienen de cualquiera de las direcciones y, a veces, de todas ellas al mismo tiempo. De manera similar, si una mujer afroamericana es afectada por encontrarse en la intersección, sus heridas pueden ser el resultado de una discriminación por razón de sexo o de una discriminación por razón de raza". CRENSHAW citada en: SALOMÉ (2015), p. 314.

15 Autores(as) como Salomé (2015) prefieren el término "discriminación múltiple”, pero en el presente artículo preferimos la expresión discriminación interseccional.

16 “(...) aquello que resulta verdaderamente importante en esta materia es que se tome en cuenta que la discriminación estructural tiene una faceta o dimensión colectiva o grupal definitoria. Ciertamente, esto no implica descartar que las personas individualmente consideradas puedan experimentar la discriminación estructural, pues sí lo hacen. Lo que se quiere decir es que la razón por la que esto sucede es porque comparten o se les atribuye unas características, rasgos o prejuicios propios de una colectividad." María José AÑón citada en: SALOMÉ (2017), p. 53.

17 “(...) el Comité considera que el término "discriminación" (...) debe entenderse referido a toda distinción, exclusión, restricción o preferencia que se basen en determinados motivos, como la raza, el color, el sexo, el idioma, la religión, la opinión política o de otra índole, el origen nacional o social, la posición económica, el nacimiento o cualquier otra condición social, y que tengan por objeto o por resultado anular o menoscabar el reconocimiento, goce o ejercicio, en condiciones de igualdad, de los derechos humanos y libertades fundamentales de todas las personas (...) Sin embargo, el goce en condiciones de igualdad de 
En esta definición están plasmados -aunque no del todo- los avances en el contenido constitucionalmente protegido del derecho/principio de igualdad y no discriminación. Así, cuando la referida Observación General hace referencia a "toda distinción, exclusión, restricción o preferencia" amplía el rango de actos u omisiones que pueden ser considerados discriminatorios y no sólo se limita a indebidas distinciones. Asimismo, cuando la Observación General describe todos los motivos considerados discriminatorios, recurre a una cláusula abierta final de "cualquier otra condición social", con lo cual permite una interpretación dinámica y evolutiva de la discriminación tomando en cuenta el contexto de cada momento y lugar.

Por otro lado, cuando la Observación General No 18 menciona las posibles consecuencias de un trato discriminatorio dirigidas a "anular o menoscabar el reconocimiento, goce o ejercicio, en condiciones de igualdad, de los derechos humanos y libertades fundamentales de todas las personas", claramente incorpora el contenido de la igualdad sustancial o de oportunidades al referirse al "goce o ejercicio, en condiciones de igualdad" de derechos y libertades. Finalmente, cuando la Observación General precisa que "el goce en condiciones de igualdad de los derechos y libertades no significa identidad de trato en toda circunstancia", abre la puerta a acciones positivas y políticas públicas de favorecimiento de determinados sectores o grupos sociales en condiciones de vulnerabilidad.

\section{Evolución de la noción de pueblos indígenas e interculturalidad en América Latina y el Perú}

Aquí también desarrollamos brevemente la evolución y debate que recurrentemente surge en torno a qué personas deben ser consideradas indígenas en el Perú y América Latina. Inclusive la denominación de "indígena” es materia de cuestionamiento y sin duda ha experimentado -y experimenta- una evolución en el tiempo. Somos conscientes que este punto es materia de un interesante y extenso debate -más propio de la antropología que del derecho-, al que sólo nos referiremos para identificar al sujeto (o sujetos) de derecho de la igualdad y no discriminación en el plano de los derechos de los pueblos indígenas.

los derechos y libertades no significa identidad de trato en toda circunstancia (...)".COMITÉ De Derechos Humanos de NaCiones Unidas (1989). 
En el plano individual, durante gran parte de nuestra historia colonial y republicana la expresión "indio" o "indígena" ha tenido una connotación peyorativa: se entendía que referirse o llamar a una persona como "indígena” o "indio", era discriminatorio, casi un insulto. Al respecto, la Comisión de la Verdad y Reconciliación (CVR) documentó que la terrible violencia que padecieron miles de peruanos durante los años del conflicto armado interno durante las décadas de los ochentas y noventas del siglo XX, solía ir acompañada de insultos étnico-raciales ${ }^{18}$ como "cholo de mierda", "serrano de mierda" "indio de mierda", ${ }^{19}$ al punto que el Informe Final de la CVR tiene un capítulo titulado "Violencia y desigualdad racial y étnica" y determinó, entre otros hallazgos, que el 75\% de las víctimas mortales fueron quechuahablantes y que el 50\% de las víctimas mortales se produjeron en Ayacucho, una región altoandina con población predominantemente indígena. ${ }^{20}$

Años atrás, durante el Gobierno del General Juan Velasco Alvarado (19681975) se intentó reivindicar -aunque en forma limitada y sin favorecer a los pueblos indígenas amazónicos- ${ }^{21}$ a los indígenas de diversas maneras -como la reforma agraria que hasta el día de hoy levanta polémica- y una de ellas fue denominarlos - reivindicativamente- como "campesinos". De esta manera, se formaron y promovieron "comunidades campesinas" en las regiones altoandinas y costeñas y “comunidades nativas" en la amazonia, reivindicándolos a partir de su vínculo de trabajo con la tierra.

Si bien en ese momento ello supuso una limitada y sesgada reivindicación histórica para los pueblos indígenas, muchos años después la auto-identificación ha

18 Cabe precisar que en el presente artículo usamos la denominación "étnico-racial" en los términos que proponen RodríGUEZ y BAQUero (2015), p. 19: “(...) etnicidad -el sistema asimétrico de estatus que asigna valores distintos a grupos sociales según sus rasgos culturales- o la raza -el sistema asimétrico de estatus que asigna valores distintos a grupos sociales en función de su color de piel y rasgos fenotípicos-. Aunque la distinción conceptual entre etnicidad y raza es central para nuestro análisis, en algunos pasajes del texto usamos el adjetivo compuesto "étnico-racial" para agrupar los dos tipos de reclamos y discriminaciones (...)".

19 Mensajes del Informe Final de la CVR: Víctimas (2006).

20 Mensajes del Informe Final de la CVR: Víctimas, (2006).

21 "A lo largo del siglo se implementaron también en la región distintos programas de reforma agraria, con los que se buscaba conseguir una distribución más justa de la propiedad de las tierras, en primer término, en México, con la revolución de principios de siglo, luego en Guatemala en los años cuarenta, en el Estado Plurinacional de Bolivia en los años cincuenta y, a partir de los años sesenta, en otros países, bajo el impulso de la Alianza para el Progreso, auspiciada por los Estados Unidos. Sin embargo, no se reconoció el autogobierno y las reformas agrarias no incidieron en el origen del problema, debido a varios factores: el indígena fue tratado como campesino, no se reconoció el carácter comunitario de la tierra, se adjudicaron terrenos poco fértiles y muy alejados de los centros de comercio, y la reforma agraria no llegó a los indígenas de la Amazonia ni de las llamadas "tierras bajas". Popolo (2017), pp. 28-29. 
ido migrando en nuestro país hacia la denominación “indígena”. Poco a poco y hasta la actualidad, muchos de los hijos y nietos de los otrora campesinos(as), cada vez más se auto-identifican como indígenas tanto en las regiones altoandinas (quechuas o aymaras) como en la amazonia (awajún, shipibo, ashaninkas y otros pueblos).

Ahora bien, en el plano colectivo se ha dado también una evolución y debate en la denominación y auto-identificación. Como acabamos de señalar, en el Perú de campesinos y nativos se ha ido migrando a la expresión "indígena” en las regiones altoandinas y amazónicas, pero ello también ha sido puesto en tela de juicio si se toma en cuenta otras denominaciones usadas en algunos países de las Américas e instrumentos internacionales. Así, algunos pueblos prefieren auto-denominarse "Pueblos Originarios" para enfatizar que fueron los primeros que ocuparon este continente mucho antes de la conquista y colonización europea. En una línea similar de razonamiento se inscribe la expresión "First Nations" o "primera naciones" usada en Canadá para referirse a los pueblos indígenas.

$\mathrm{Al}$ respecto, consideramos que son los propios pueblos y personas los que tienen que decidir cómo denominarse o definirse, bajo el criterio de auto-adscripción que hoy se considera determinante sobre el particular. Además, la definición de quiénes son indígenas ha sido considerado por el TC como "una cuestión prioritaria para el Estado peruano". ${ }^{22}$

Fue el artículo $1.2^{\circ}$ del Convenio OIT 169 el primer instrumento internacional en establecer que la auto-adscripción, auto-percepción o "conciencia de su identidad indígena" debía ser considerado el "criterio fundamental" para determinar qué grupos sociales pueden ser calificados como pueblos indígenas: " $\mathrm{La}$ conciencia de su identidad indígena o tribal deberá considerarse un criterio fundamental para determinar los grupos a los que se aplican las disposiciones del presente Convenio."

Posteriormente, el artículo 33.1 ${ }^{\circ}$ de la Declaración de las Naciones Unidas sobre los derechos de los pueblos indígenas no sólo ratificó la auto-adscripción como criterio fundamental para identificarse como “indígena”, sino que además lo elevó a derecho fundamental a definir o determinar su propia identidad o pertenencia indígena: "Los pueblos indígenas tienen derecho a determinar su propia identidad o pertenencia conforme a sus costumbres y tradiciones [...]".

22 Sentencia del Tribunal Constitucional No 0004-2018-PI/TC, de 20 de julio de 2018, párrafo 15. 
Finalmente, el artículo I.2 $2^{\circ}$ de la Declaración americana sobre los derechos de los pueblos indígenas ratificó a la auto-adscripción o auto-identificación como el "criterio fundamental" para determinar si una persona o grupo social ("en forma individual o colectiva") se considera -o no- indígena, criterio que -a la vez- es un derecho fundamental también ("Los Estados respetarán el derecho a dicha autoidentificación como indígena”). ${ }^{23}$

Es importante destacar que tanto la Declaración de Naciones Unidas como la Declaración americana, precisan convenientemente que esta auto-adscripción o auto-identificación será ejercida conforme a las prácticas o instituciones propias de cada pueblo indígena o conforme a sus costumbres o tradiciones y no conforme los criterios que pretendan imponerles los Estados.

En ese sentido, en el presente artículo nos inclinamos por la expresión "pueblos indígenas" porque -hasta el momento- es de mayoritaria aceptación por ellos mismos en el Perú y, por otro lado, porque es la expresión más utilizada por los instrumentos internacionales. Sin embargo, también somos conscientes que la auto-identificación es dinámica y responde a cada momento histórico, por lo que prevemos que a futuro probablemente se migre a otras denominaciones como "pueblos originarios", ${ }_{24}$ "nacionalidades indígenas" o "primeras naciones", que son las expresiones que buscan poner el acento al hecho que fueron los primeros que poblaron el continente americano, antes de la llegada de los colonizadores europeos o de otras olas migratorias de África o de Asia y, también, antes de la delimitación de las fronteras de los actuales Estados nacionales.

\section{Discriminación estructural, indirecta e interseccional en contra de los pueblos indígenas}

Hasta aquí sólo hemos desarrollado -brevemente- el actual estado del arte en torno, por un lado, al contenido constitucional del derecho/principio de igualdad y no discriminación y, por otro lado, a la evolución del término "indígena” en el Perú.

23 "La autoidentificación como pueblos indígenas será un criterio fundamental para determinar a quienes se aplica la presente Declaración. Los Estados respetarán el derecho a dicha autoidentificación como indígena en forma individual o colectiva, conforme a las prácticas e instituciones propias de cada pueblo indígena." $24 \mathrm{Al}$ respecto, el Ministerio de Cultura del Perú, tiene una base de datos que ya se denomina "Base de datos de pueblos indígenas u originarios" (https://bdpi.cultura.gob.pe/) 
Ahora nos corresponde caracterizar la discriminación de la que son objeto las personas y pueblos indígenas que, en nuestra opinión, es -sobre todo- estructural e indirecta y, con frecuencia, también interseccional. Ciertamente ello no niega la posibilidad que, en ocasiones, algunas personas indígenas también puedan padecer discriminación formal que, sin duda, también debe ser combatida, pero en el presente artículo deseamos enfatizar el contexto histórico y estructural discriminatorio que enfrentan los pueblos indígenas en nuestro continente $y$, en consecuencia, la conveniencia que la jurisprudencia constitucional ajuste sus decisiones en aras de contribuir a cambiar dicha realidad.

Tal es la historia de oprobio, explotación y discriminación de los pueblos indígenas en el continente americano, que en la ceremonia en la que recibió el Premio Nobel de literatura el año 2010, el escritor peruano Mario Vargas Llosa reconoció que la conquista europea de América "fue cruel y violenta", que los indígenas siguieron siendo explotados por las nacientes Repúblicas y que la emancipación indígena "sigue siendo una asignatura pendiente en toda América Latina".25

La Comisión Económica para América Latina y el Caribe (CEPAL) publicó el 2017 el Informe "Los pueblos indígenas en América (Abya Yala), desafíos para la igualdad en la diversidad", ${ }^{26}$ en el que volvió a documentar la situación de desigualdad histórica y estructural en la que se hayan los pueblos indígenas desde la colonización europea de nuestro continente en el siglo XV. ${ }^{27}$

Esta situación cobra especial actualidad hoy en día no sólo porque los pueblos indígenas hacen parte de la agenda prioritaria de igualdad y no discriminación en

25 "La conquista de América fue cruel y violenta, como todas las conquistas, desde luego, y debemos criticarla, pero sin olvidar, al hacerlo, que quienes cometieron aquellos despojos y crímenes fueron, en gran número, nuestros bisabuelos y tatarabuelos, los españoles que fueron a América y allí se acriollaron, no los que se quedaron en su tierra. Aquellas críticas, para ser justas, deben ser una autocrítica. Porque, al independizarnos de España, hace doscientos años, quienes asumieron el poder en las antiguas colonias, en vez de redimir al indio y hacerle justicia por los antiguos agravios, siguieron explotándolo con tanta codicia y ferocidad como los conquistadores, y, en algunos países, diezmándolo y exterminándolo. Digámoslo con toda claridad: desde hace dos siglos la emancipación de los indígenas es una responsabilidad exclusivamente nuestra y la hemos incumplido. Ella sigue siendo una asignatura pendiente en toda América Latina. No hay una sola excepción a este oprobio y vergüenza." VARGAS LlOSA (2010).

26 Popolo (2017).

27 "En las últimas décadas América Latina ha experimentado, a diferentes velocidades y con rasgos variados en los distintos países, significativos progresos en su desarrollo económico y social (...). Sin embargo (...). Los pueblos indígenas forman parte de los colectivos más desfavorecidos, como resultado de complejos procesos sociales e históricos que se iniciaron hace más de 500 años y que fueron estableciendo prácticas discriminatorias persistentes hasta el presente e implicaron un despojo sistemático de sus territorios, con graves consecuencias para su bienestar." Popolo (2017), p. 17. 
nuestro continente, sino también por la fuerte presión que sufren las tierras y territorios indígenas por el modelo extractivista primario exportador aún vigente. ${ }^{28}$

Por ello, coincidimos con el citado Informe de la CEPAL cuando sostiene que la inclusión de los pueblos indígenas supone también un nuevo paradigma de desarrollo, en el que se debe incorporar las visiones, diversidad, conocimientos e intereses indígenas. En otras palabras, transitar de un solo modelo de "desarrollo" a diversos modelos de desarrollo, todos válidos, en los que se incorporen los intereses y conocimientos indígenas, en especial, los que buscan utilizar en forma sostenible el ambiente y los recursos naturales. ${ }^{29}$

Esta contemporánea valoración positiva del aporte de los pueblos indígenas al cuidado del ambiente y los recursos naturales, se ha expresado no sólo en diversos instrumentos internacionales sino también en documentos oficiales de la Iglesia católica. Al respecto, en el documento de "Aparecida" del año 2007 aprobado por la V Conferencia General del Episcopado Latinoamericano y del Caribe, la Iglesia católica también constató que la sociedad tiende a "menospreciar" a los indígenas y que su situación social "está marcada por la exclusión y la pobreza”.3

En el caso del Perú, diversos documentos oficiales e instituciones estatales también han corroborado la postergación y discriminación histórica y estructural de los pueblos indígenas, lo que se expresa no sólo en situaciones de pobreza extrema o bajo índices de desarrollo humanos de muchas comunidades indígenas de la Amazonia o regiones altoandinas, sino también en una persistente discriminación social, étnico-racial y cultural que se expresa, entre otros indicadores, en el tratamiento que reciben por parte de los medios de comunicación.

28 “(...) en la región, como se examina en este estudio, existen más de 800 pueblos indígenas, con una población cercana a los 45 millones de personas, que se caracterizan por su amplia diversidad demográfica, social, territorial y política, e incluyen desde pueblos en aislamiento voluntario hasta pueblos que están presentes en grandes asentamientos urbanos. A esto se agrega que el crecimiento económico registrado en la región es altamente dependiente de los recursos naturales y de sus precios internacionales (...). La reprimarización de la economía ha ocasionado fuertes presiones sobre los territorios de los pueblos indígenas y ha desencadenado numerosos conflictos socioambientales todavía no resueltos." Popolo (2017), p. 18.

29 Popolo (2017), pp. 18-19.

30 "Los indígenas y afroamericanos (...) La sociedad tiende a menospreciarlos, desconociendo su diferencia. Su situación social está marcada por la exclusión y la pobreza (...). Hoy, los pueblos indígenas y afros están amenazados en su existencia física, cultural y espiritual; en sus modos de vida; en sus identidades; en su diversidad; en sus territorios y proyectos. Algunas comunidades indígenas se encuentran fuera de sus tierras porque éstas han sido invadidas y degradadas, o no tienen tierras suficientes para desarrollar sus culturas (...)". Documento de Aparecida, párrafos 89-90. 
Tal como lo muestra la Encuesta Nacional de Hogares y condiciones de vida (ENAHO) aplicada por el Instituto Nacional de Estadística e Informática (INEI) durante los años 2014, 2015, 2016, 2017 y 2018 en el Perú y el XII Censo de Población y VII de viviendo realizado el año $2017,{ }^{31}$ el nivel de pobreza es mayor en el caso de los pueblos indígenas, en comparación con la población no indígena. Para tal comparación, la Base de datos de pueblos indígenas u originarios (BDPI) del Ministerio de Cultura ha tomado "la variable de lengua materna, principalmente, y la pertenencia a un pueblo indígena tomando en cuenta el carácter declarativo de la encuesta"32; por lo que desprendemos que para el Ministerio de Cultura la principal variable ha sido la lengua materna y complementariamente la auto-adscripción o auto-identificación, probablemente porque esta segunda variable recién comenzó a tomarse en cuenta en este tipo de censos a partir del 2017.

Así, según esta información estadística disponible, en el 2018 el 30\% de la población cuya lengua materna es el quechua, el 34\% de la población que habla aimara y el $55 \%$ de la población que habla otra lengua indígena (asumimos amazónicas principalmente), se encontraban en situación de pobreza. En contraste, el $17 \%$ de la población que habla castellano, se encontraba el año 2018 en situación de pobreza. ${ }^{33} \mathrm{Si}$ consideramos a toda la población cuya lengua materna es indígena, el porcentaje en situación de pobreza fue del 32.3\% en el 2018, que casi duplica el $17 \%$ de población cuya lengua materna es el castellano y que se encuentra en situación de pobreza. ${ }^{34}$

En el caso de América Latina, los indicadores de mayor pobreza entre la población indígena son similares. Según el Informe "Pobreza y derechos humanos" de la CIDH del año 2017, la pobreza tiene un impacto diferenciado más grave en los pueblos indígenas en comparación con la población en general..$^{35}$

31 Tomado de la sección "Indicadores sociodemográficos" de la Base de datos de pueblos indígenas u originarios del Ministerio de Cultura del Perú (https://bdpi.cultura.gob.pe/indicadores-sociodemograficos)

32 BDPI (2019). Tomado de la sección "Indicadores sociodemográficos" de la Base de datos de pueblos indígenas u originarios del Ministerio de Cultura del Perú (https://bdpi.cultura.gob.pe/ indicadores-sociodemograficos).

33 Situación y Nivel De Pobreza (2019), p. 1. [Ebook]. Retrieved from https://bdpi.cultura.gob.pe/sites/default/files/archivos/paginas_internas/items/Situacion\%20y\%2onivel\%2ode\%2opobreza\%2oenaho\%2o 2018.pdf

34 Situación y Nivel de POBREZa (2019), p. 2. [Ebook]. Retrieved from https://bdpi.cultura.gob.pe/sites/default/files/archivos/paginas_internas/items/Situacion\%2oy\%2onivel\%2ode\%2opobreza\%2oenaho\%2o 2018.pdf

35 "La Comisión observa que los pueblos indígenas en las Américas continúan viéndose desproporcionadamente afectados por la pobreza y la pobreza extrema, en comparación con la población en general. La 
Esta información estadística revela, claramente, la interseccionalidad que con frecuencia suele darse en el Perú y América Latina entre la doble condición de indígena y pobre, con mayor gravedad aún en el caso de los pueblos indígenas amazónicos.

Por otro lado, el Informe No 002-2019-DP/AMASPPI/PPI publicado por la Defensoría del Pueblo, ${ }^{36}$ identificada diversos ámbitos en los que las mujeres indígenas tienen especial dificultad para acceder o realizar sus derechos a la salud, educación, propiedad o participación política, describiendo una situación estructural de postergación y discriminación que requiere sostenidas políticas públicas para resolverla.

En el caso de los medios de comunicación, la Comisión Nacional contra la discriminación (CONACOD), adscrita al Ministerio de Justicia y Derechos Humanos del Perú, publicó un interesante "Informe sobre la discriminación en medios de comunicación en el Perú, con especial énfasis en la discriminación étnico-racial". ${ }^{37} 38$

pobreza afecta al $43 \%$ de los hogares indígenas del hemisferio; cifra que constituye el doble de la proporción del problema en hogares no indígenas. A su vez, el $24 \%$ de todos los hogares indígenas viven en condiciones de pobreza extrema; es decir la pobreza extrema afecta a estas comunidades 2.7 veces de forma más frecuente que a los hogares no indígenas." CIDH (2017), párrafo 357.

36 Defensoría De PUEblo (2019).

37 Dicho informe da cuenta "(...) de los contenidos discriminatorios difundidos a través de los medios de comunicación en el Perú, con especial énfasis en la discriminación étnico-racial a través de los programas de radio y televisión, así como de medios escritos (...)" Minjus (2019), p. 4. Al respecto, el referido informe también afirma que "(...) otro grupo tratado de manera estigmatizante y peyorativa por los medios de comunicación es el de personas de pueblos indígenas u originarios, personas afrodescendientes y personas de origen o ascendencia andina o amazónica ( ) con frecuencia es materia de tratamiento discriminatorio y racista por algunos medios y/o programas (...)”. Minjus (2019), p. 9.

38 Un caso emblemático de esta situación de discriminación cultural y étnico-racial de carácter estructural en el Perú, es el del personaje "La paisana Jacinta" que caracterizó durante mucho tiempo un actor cómico en la televisión. Frente a ello, un grupo de mujeres indígenas -apoyadas por organizaciones de derechos humanos- interpuso un proceso constitucional de amparo dirigido a que no se siguiera caracterizando ni difundiendo este personaje; pretensión que fue declarada fundada por un juzgado de la ciudad del Cusco en el año 2019. Entre otros fundamentos, la jueza sostuvo en su sentencia que: "resulta concreto que el personaje "Paisana Jacinta" representado por Jorge Benavides Gastello y difundido por el canal de Frecuencia Latina, y por otros medios a través de internet o en determinadas circunstancias a través de un circo o de una película, etc., presenta a la mujer indígena andina como una persona sucia, sin dientes, totalmente desalineada, vulgar, grosera, torpe, de escasa capacidad intelectual y que es maltratada generalmente por los citadinos dadas sus características (...). Toda esta caracterización negativa de una mujer que llega de provincia a Lima a buscar trabajo, no solo genera sino refuerza un estereotipo o perjuicio negativo relativo a un grupo social, que por circunstancias distintas arriban a las grandes ciudades provenientes de la región andina. Esta circunstancia no únicamente ocasiona, promueve y refuerza la discriminación por origen étnico y cultural (...)" Caso Paisana Jacinta (2019), p. 2.3. 
Este contexto histórico y estructural en el que se produce la discriminación en contra de los pueblos indígenas, ya ha sido incorporado por la Comisión interamericana de derechos humanos (CIDH) en sus informes. ${ }^{39}$ En el caso específico de la discriminación étnico racial, la $\mathrm{CIDH}$ "ha entendido que estas situaciones de discriminación no pueden ser analizadas sin considerar los factores estructurales e históricos que le dan lugar." 40

Por su parte, la jurisprudencia de la Corte interamericana de derechos humanos (CoIDH) no sólo incorpora esta noción de discriminación estructural, sino que le suma el enfoque de interseccionalidad, al desarrollar en el caso Gonzales Lluy vs Ecuador la especial vulnerabilidad en la que se pueden encontrar personas que sufren múltiples discriminaciones por su condición de pobreza, de mujer o de niño. ${ }^{41}$

En sentido similar se pronunció la CoIDH en el caso "Trabajadores de la hacienda verde vs. Brasil”, en el que los trabajadores fueron sometidos a condiciones casi de esclavitud por diversas condiciones estructurales de pobreza, marginación y analfabetismo que se intersectaron para hacerlos mucho más vulnerables. ${ }^{42}$

39 "El concepto de discriminación estructural ha sido destacado por la CIDH con un particular énfasis en la necesidad de realizar una valoración amplia del contexto histórico, temporal y geográfico en casos donde se presenten patrones de discriminación... En este sentido, al verificar la existencia de una situación de discriminación estructural, la Comisión ha entendido que el Estado debe tomar medidas acordes para disminuir y eliminar la situación de inferioridad o exclusión contra determinada persona o grupo de personas." CIDH (2019a), párrafos 39-40.

$40 \mathrm{CIDH}$ (2019b), párrafo 76.

41 "La Corte constata que la discriminación contra Talía ha estado asociada a factores como ser mujer, persona con VIH, persona con discapacidad, ser menor de edad, y su estatus socio económico. Estos aspectos la hicieron más vulnerable y agravaron los daños que sufrió." Corte IDH. Caso Gonzales Lluy y otros vs. Ecuador. Excepciones preliminares, fondo, reparaciones y costas. Sentencia de 1 de septiembre de 2015, párrafo 285 .

42 "La Corte estima que el Estado incurre en responsabilidad internacional en aquellos casos en que, habiendo discriminación estructural, no adopta medidas específicas respecto a la situación particular de victimización en que se concreta la vulnerabilidad sobre un círculo de personas individualizadas (...). La Corte constata, en el presente caso, algunas características de particular victimización compartidas por los 85 trabajadores rescatados el 15 de marzo de 2000: se encontraban en una situación de pobreza; provenían de las regiones más pobres del país, con menor desarrollo humano y perspectivas de trabajo y empleo; eran analfabetas, y tenían poca o nula escolarización (...). Lo anterior los colocaba en una situación que los hacía más susceptibles de ser reclutados mediante falsas promesas y engaños. Dicha situación de riesgo inmediato para un grupo determinado de personas con características idénticas y originarios de las mismas regiones del país, tiene orígenes históricos y era conocida desde, al menos, 1995, cuando el Gobierno de Brasil reconoció expresamente la existencia de "trabajo esclavo" en el país (...)". Corte IDH. Caso Trabajadores de la Hacienda Brasil Verde vs. Brasil. Excepciones Preliminares, Fondo, Reparaciones y Costas. Sentencia de 20 de octubre de 2016, párrafos 338-339. 
En consecuencia, si por un lado tomamos en cuenta la condición histórica y estructural de discriminación de la que han sido y son víctimas los pueblos indígenas en el Perú y en las Américas y, por otro lado, que los estándares interamericanos y algunos informes oficiales nacionales reconocen la discriminación estructural e interseccional que enfrentan los pueblos indígenas en los hechos, en el ámbito del derecho constitucional también deberían haber pronunciamientos que reconozcan y desarrollen esta discriminación. Inclusive, si las condiciones vigentes en nuestra sociedad y el diseño institucional del Estado contribuyen a esta situación, en ocasiones la discriminación no necesariamente será intencional, sino que será fruto de una inercia histórica o cultural o prácticas sociales, configurándose así lo que se conoce como discriminación indirecta.

Así, la situación de las mujeres indígenas es de creciente preocupación tanto a nivel nacional como internacional. En ellas con frecuencia se condensan o "intersectan" diversas condiciones de vulnerabilidad, lo que hace más intensa y grave la discriminación de la pueden ser víctima: indígena, mujer, pobre o niña. Por ello, ONU mujeres hace especial seguimiento a las políticas públicas o medidas que los Estados adoptan -o deberían adoptar- para mejorar las condiciones de la mujer y niña de zonas rurales en el mundo. ${ }^{43}$

Otro ejemplo de potencial discriminación interseccional es la situación de las personas de orientación sexual o identidad de género diferente al interior de las comunidades indígenas, ${ }^{44} \mathrm{o}$ de las personas adultas mayores, con alguna discapacidad o los niños al interior de las mismas. Si bien, como ya hemos señalado, en el derecho de los derechos humanos de los pueblos indígenas el sujeto de derecho es colectivo, esto es, es el propio pueblo indígena como persona jurídica, ${ }^{45} \mathrm{sin}$ embargo ello no impide el reconocimiento de otros sujetos de derecho, individuales o colectivos, al interior de las propias comunidades, con derechos, intereses o necesidades diferenciadas, que podría estar ubicándolos en situaciones de mayor

43 Organización de Naciones Unidas Mujeres (2019).

$44 \mathrm{Al}$ respecto, la CIDH (2015b), párrafo 265, ha subrayado "La Comisión subraya que las personas indígenas con identidades sexuales no normativas sufren de múltiples e interrelacionadas formas de violencia y discriminación debido a su identidad y sexualidad indígenas, su orientación sexual y/o identidad de género". 45 Sobre el particular, en la Opinión Consultiva OC-22/16 del 26 de febrero del 2016, la Corte interamericana precisó que las personas jurídicas no son titulares de derecho ante el sistema interamericano de derechos humanos, con excepción de los sindicatos de trabajadores y pueblos indígenas, reforzando así la naturaleza colectiva de muchos de los derechos fundamentales de éstos últimos. 
vulnerabilidad, pues a su condición indígena en situación de pobreza, podría sumarse la de mujer, niño o adulto mayor. ${ }^{46}$

Finalmente, la CIDH también tomó en cuenta esta interseccionalidad en la doble condición de indígena en situación de pobreza en su informe sobre Guatemala del 2015. ${ }^{47}$

\section{El derecho a la igualdad y no discriminación de los pueblos indígenas en la jurisprudencia del Tribunal Constitucional peruano}

Tal como hemos visto en el punto anterior del presente artículo, el sistema interamericano de derechos humanos ya ha construido estándares en torno al derecho a la igualdad y no discriminación de los pueblos indígenas, basados en la noción de discriminación estructural e interseccional. Por su parte, el Ministerio de Cultura, el Ministerio de Justicia y derechos humanos y la Defensoría del Pueblo han producido informes o documentos oficiales que dan cuenta de esta realidad histórica y estructural de discriminación en contra de los pueblos indígenas en Perú.

Así que ahora toca analizar si el Tribunal Constitucional (TC) peruano, por un lado, ha tenido pronunciamientos específicos en torno al derecho a la igualdad y no discriminación de las personas y pueblos indígenas y, por otro lado, cuáles son los contenidos, técnicas, estándares o principios de interpretación constitucionales que ha desarrollado hasta el momento. Al año 2019, el TC tenía cuatro (o4) sentencias y un (01) auto jurisdiccional vinculados -directa o indirectamente- al derecho a la igualdad y no discriminación por motivos étnico-raciales en contra de personas y pueblos indígenas:

1. STC No 0o889-2017-PA/TC, Derecho a comunicarse en su propia lengua indígena. Una mujer quechuahablante interpone una demanda de amparo en contra de la Municipalidad Provincial de Carhuaz, solicitando que se le permita continuar realizando la venta de sus productos de manera ambulatoria en el mismo espacio y horario, que viene ocupando hace más de

46 Por ello, la CIDH (2014) ya "ha reconocido consistentemente, que ciertos grupos de mujeres enfrentan discriminación sobre la base de más de un factor a lo largo de sus vidas, tales como su edad joven, su raza y su origen étnico, y que esta discriminación multifacética aumenta su exposición a actos de violencia (...)”.

47 "La discriminación histórica de los pueblos indígenas se manifiesta en la falta de respeto y vigencia de los derechos humanos de los cuales son titulares, los coloca en una situación pobreza y pobreza extrema, y los ubica dentro de la mayoría de la población en los departamentos con los más altos índices de exclusión social (...). Esta permanencia de la correlación entre el mapa social de la pobreza y la marginación de los pueblos indígenas evidencia el profundo arraigo de una discriminación structural (...)”. CIDH (2015c), pp. 70-79. 
30 años. Supuestamente había suscrito una carta de compromiso pero que desconoce su contenido debido a que es quechuahablante y analfabeta en el idioma castellano. Sostiene que hay discriminación contra ella debido a que hay otra persona que si puede comercializar sus productos en el mismo espacio público y sin ningún tipo de restricción de horario, mientras que a ella le han dado sólo 3 horas.

2. STC No 02765-2014-PA/TC, Caso comunidad Montevideo. Cuatro personas interponen amparo contra el presidente de la Comunidad Campesina, el Alcalde Distrital, el juez de paz y el Comité de la Ronda Campesina de Montevideo (Amazonas), con la finalidad que la destitución que se les impuso por medio de una asamblea, no les sea aplicable. Además, solicitan que sus terrenos les sean devueltos.

3. STC No 07009-2013-PHC/TC, Caso violencia sexual contra niñas indígenas. El Presidente de Comunidad Nativa Tres Islas (Madre de Dios), interpone hábeas corpus a favor de Juan Villar Vargas y Herbert Cusurichi Payaba, solicitando tutela de derecho a libertad personal de beneficiarios, así como el respeto de autonomía jurisdiccional de la comunidad nativa a la que pertenecen. Manifiesta que los beneficiarios vienen siendo acusados por la presunta comisión del delito contra la libertad sexual (violación sexual) de menor de edad, por haber sostenido relaciones sexuales con dos menores pertenecientes a la comunidad nativa (de 13 y 12 años respectivamente), dentro del territorio de la comunidad, pero que dicha conducta fue con pleno consentimiento de las menores, siendo incluso que Herbert Cusurichi Payaba convivió y tuvo un hijo con una de ellas de manera pacífica. Sin embargo, la Policía Nacional ingresó a su territorio sin su consentimiento y detuvo a Juan Villar Vargas, a quien se le viene sometiendo a un proceso penal sin tomar en consideración que dicha materia ha sido resuelta por la jurisdicción indígena como consta del Acta de Asamblea General.

4. AUTO STC 07009-2013-PHC/TC, Caso violencia sexual contra niñas indígenas. El recurrente solicita se aclaren los argumentos 29, 32 y 35 de la sentencia 07009-2013-PHC/TC, en los que se señala que el Estado cede parte de su jurisdicción a la justicia indígena y en los que se establece la competencia material penal de la justicia indígena.

5. STC No 008-53-2015-PA/TC, Caso niñas rurales. Marleni Cieza y Elita Cieza presentan amparo contra Unidad de Gestión Educativa Local (UGEL) 
de Utcubamba (Amazonas), a fin que se les reconozca su derecho a estudiar en el primer grado de educación secundaria en la I. E. 16957 Jesús Divino Maestro, del caserío La Flor, distrito de Cumba, provincia de Utcubamba, Amazonas. Sustentan su demanda en que se ha vulnerado su derecho a la educación, igualdad y a no ser discriminadas, dado que la UGEL observó sus matrículas debido a que no contaban con las edades para ser matriculadas (son mayores de edad), indicando además que no podían acogerse al derecho de continuidad. En el caserío en el que viven no existe ninguna institución de educación básica alternativa secundaria, por lo que se vieron forzadas a continuar sus estudios en la I. E. 16957 Jesús Divino Maestro, que se encuentra a una hora y media de camino desde el lugar donde viven. Mencionan que les resulta imposible aceptar la modalidad básica alternativa, pues la institución educativa que cuenta con esta se encuentra en la capital Bagua Grande. Todos los días deberían caminar dos horas por camino de herradura, muchas veces bajo lluvia, hasta llegar a un lugar donde existe movilidad, y de allí viajar durante dos horas para llegar a Bagua Grande, que tiene un Centro de Educación Básica Alternativa que funciona en horario nocturno.

Este resumen de los pronunciamientos del TC que hemos podido identificar hasta el año 2019 en torno -en forma directa o indirecta- al derecho a la igualdad y no discriminación de las personas y pueblos indígenas, nos mueve a los siguientes comentarios:

1. Es un número muy reducido de pronunciamientos jurisdiccionales que desarrollan el derecho a la igualdad y no discriminación de las personas y pueblos indígenas. Es más, los pronunciamientos que abordan esta temática en forma directa son sólo dos (02): i) STC No 00889-2017-PA/TC (derecho a comunicarse en su propia lengua indígena) y ii) STC No oo853-2015-PA/TC (caso niñas rurales), con la precisión que, aunque en este segundo caso el TC sostiene que no va a pronunciarse sobre el derecho a la igualdad, ${ }^{48}$ en sus fundamentos y en la parte resolutiva sí lo hace vinculado al derecho a la educación.

48 "Finalmente, con relación a la alegada afectación del principio-derecho a la igualdad y no discriminación, este Tribunal considera que, a la luz de lo expuesto por las demandantes y en el entendido de que no se ha ofrecido un tertium comparationis que evidencie tal situación, no corresponde emitir pronunciamiento de fondo sobre el particular, ya que el problema jurídico planteado versa, en puridad, sobre si se ha conculcado 
2. En los otros tres (o3) pronunciamientos, hacemos el esfuerzo de interpretar que el TC se refiere en forma indirecta al derecho a la igualdad y no discriminación de las personas y pueblos indígenas, cuando establece que los derechos fundamentales -como la igualdad y no discriminación- también se pueden esgrimir ante la jurisdicción indígena (artículo $149^{\circ}$ Constitución): i) STC No $02765-2014-\mathrm{PA} / \mathrm{TC}$ (caso comunidad Montevideo) y ii) STC No 07009-2013-PHC/TC (caso violencia sexual contra niñas indígenas) (sentencia de fondo y auto de aclaración).

3. Consideramos que el punto anterior es muy importante de cara a posibles casos de discriminación interseccional de mujeres, niños, adultos mayores o personas con orientación o identidad de género diferente, que podrían ventilarse ante la jurisdicción indígena y que, eventualmente, podrían merecer control y tutela constitucional por parte del TC.

4. Si bien la sentencia del TC en el caso de violencia sexual contra niñas indígenas (STC No 07009-2013-PHC/TC) es criticable en el extremo que suma la potestad punitiva del Estado, como límite a la jurisdicción indígena pese a no estar contemplado en el artículo $149^{\circ}$ de la Constitución, ${ }^{49}$ rescatamos de dicho pronunciamiento que el TC deja claro que el interés superior del niño o niña indígena merece especial o reforzada protección por parte del ordenamiento constitucional en relación a otros derechos fundamentales de los pueblos indígenas como su autodeterminación jurídica consagrada en el artículo $149^{\circ}$ de la Constitución.

5. Sin embargo, echamos en falta que el TC no haya aprovechado este caso como si lo hizo en el caso de las niñas rurales que de inmediato pasaremos a comentar-, para pronunciarse sobre la especial vulnerabilidad y la discriminación interseccional (menores de edad, mujeres, indígenas y pobres) que enfrentan las niñas indígenas en nuestro país, una de cuyas expresiones más dramáticas es la violencia sexual de la que pueden ser víctimas a

o no el derecho a la educación". Sentencia del Tribunal Constitucional Nºo8-53-2015-PA, de 14 de marzo de 2017 , p. 3.

$49 \mathrm{El}$ artículo $149^{\circ}$ de la Constitución ya establece que la jurisdicción indígena se ejerce "siempre que no violen los derechos fundamentales de la persona", con lo cual, cualquier decisión en materia penal de esta jurisdicción especial está sujeta a control constitucional en virtud del principio de interdicción de la arbitrariedad y, por ende, si afecta derechos fundamentales -como en este caso la libertad sexual de menores de edad, en nuestra opinión-, podrá ser revisada por la justicia constitucional y eventualmente el caso derivado a la jurisdicción ordinaria. 
partir de los 12 ó 13 años de edad, como sucedió en este caso. En ese sentido, es lamentable que la sentencia bajo comentario se haya mostrado favorable al argumento del error cultural para intentar justificar este supuesto delito ante la justicia ordinaria.

6. En cambio, en el caso niñas rurales (STC No oo8-53-2015-PA/TC) el TC desarrolla algunos estándares y principios de interpretación constitucional en torno al derecho a la igualdad y no discriminación de niñas y mujeres de zonas rurales vinculado al derecho a la educación, que bien pueden extenderse a las personas o pueblos indígenas y que a futuro deberían merecer un mayor desarrollo.

7. Cabe precisar al respecto que si bien la sentencia bajo comentario se refiere a "niñas rurales" y no a "niñas indígenas", la realidad histórica y estructural de discriminación interseccional que enfrentaron las dos demandantes y que afectaba gravemente su derecho a la educación, es una realidad muy similar a la de las niñas indígenas y pueblos indígenas en general: viven en una región amazónica (el distrito de La Cumba está ubicado a las orillas del Río Marañón, provincia de Utcubamba, región Amazonas), en esa misma región de Amazonas -aunque en otras provincias- viven también diversos pueblos amazónicos, entre los que destaca el pueblo Awajun y comparten una realidad de pobreza rural y ausencia o insuficiencia de los servicios del Estado como la educación o la salud. Por ello que consideramos que esta sentencia también podría ser invocada por personas o pueblos indígenas.

8. En ese sentido, destacamos de la referida sentencia, en primer lugar, que reconoce que la falta de acceso a la educación por parte de las niñas y adolescentes rurales es una "problemática histórica"; en segundo lugar, que tal situación histórica y, nosotros agregamos estructural, las ubica en una especial "situación de vulnerabilidad"; en tercer lugar, que frente a ello el Estado tiene el "deber especial" de adoptar "medidas que favorezcan la accesibilidad a la educación inicial, primaria y secundaria" y, en cuarto lugar, que las niñas, adolescentes y mujeres mayores de edad en situación de pobreza o del ámbito rural, deben contar con "atención prioritaria..50

50 "Precisamente, estos últimos indicadores dan cuenta de la problemática histórica en el Perú relacionada con el pleno ejercicio de los derechos de las mujeres, especialmente de aquellas que se encuentran en situación de vulnerabilidad, como es el caso de las niñas y adolescentes del ámbito rural. Por ello es que el Estado tiene un deber especial en la formulación de medidas que favorezcan la accesibilidad a la educación inicial, 
9. En otro pasaje de la referida sentencia, el TC enfatiza el deber constitucional del Estado de adoptar medidas positivas a favor de sectores sociales en situación de vulnerabilidad debido a factores históricos y estructurales, como es el caso de las niñas rurales. ${ }^{51}$

10. En segundo lugar, cabe destacar que la sentencia bajo comentario toma el caso concreto para pronunciarse respecto a una realidad social que es verificable gracias a diversos indicadores estadísticos y de desarrollo humano con los que ahora se cuenta. ${ }^{52}$

11.En tercer lugar, la referida sentencia propone una respuesta constitucional a esta situación de discriminación histórica y estructural en torno al acceso a la educación, a través de la figura del "estado de cosas inconstitucional" desarrollado por otros altos tribunales constitucionales como la Corte constitucional de Colombia y que, en síntesis, supone considerar que una situación determinada, por su permanencia en el tiempo, su gravedad o extensión en una sociedad determinada o cualquier otra consideración que afecte seriamente a la sociedad en su conjunto o un sector importante de la misma, puede ser considerada incompatible con el orden constitucional y, por ende, disponer que el Estado adopte gradualmente un conjunto de medidas o políticas públicas dirigidas a revertir tal "estado de cosas inconstitucional".53

primaria y secundaria de niñas, adolescentes y mujeres mayores de edad, otorgando una atención prioritaria a aquellas que se encuentran en estado de pobreza o en el ámbito rural." Sentencia del Tribunal Constitucional No 008-53-2015-PA, de 14 de marzo de 2017, p. 31.

51 “... al Estado le corresponde remover los obstáculos históricos que han mantenido y mantienen aún en posiciones desventajosas respecto al resto de la sociedad e incluso en situaciones de desigualdad a varios grupos vulnerables, entre los que se encuentran las niñas y adolescentes que intentan acceder a la educación rural pese a todos los condicionamientos que suelen tener en contra." Sentencia del Tribunal Constitucional $\mathrm{N}^{\circ}$ oo8-53-2015-PA, de 14 de marzo de 2017, p. 58.

52 "En vista de ello, siendo este porcentaje uno de los menores a nivel nacional, puede señalarse que la situación de las recurrentes es ilustrativa de todo un sector de la población que aún no puede acceder en condiciones de igualdad a la educación básica, que es obligatoria y gratuita en las instituciones del Estado según el artículo 17 de la Constitución (...)”. Sentencia del Tribunal Constitucional Nºo8-53-2015-PA, de 14 de marzo de 2017, párrafo 53.

53 "Es claro que lo resuelto en el presente caso es directamente vinculante para las partes intervinientes. Sin embargo, el Tribunal Constitucional observa que la situación en la que se han visto ubicadas las demandantes es representativa de todo un grupo de personas que pertenecen al ámbito rural y se encuentran en estado de pobreza. Por ello, debe evaluarse si es de aplicación la técnica del estado de cosas inconstitucional y, si es así, corresponde dictar las decisiones pertinentes que coadyuven a reparar tal estado de inconstitucionalidad... De la revisión de autos y como es de público conocimiento, se puede afirmar que el caso individual de las demandantes es uno que representa en idénticas circunstancias a miles de peruanos que, por vivir en zonas 
12. En cuarto lugar, en el presente caso el TC, luego de tomar en cuenta diversos indicadores de desarrollo humanos e información estadística y de declarar "estado de cosas inconstitucional" respecto a las grandes dificultades estructurales que enfrentan las niñas, adolescentes y mayores de edad de extrema pobreza en zonas rurales para acceder a la educación, dispuso que el Ministerio de Educación adopte diversas políticas públicas en un plazo de cuatro (04) años y priorizando determinadas regiones del país, dirigidas a revertir esta situación de discriminación histórica y estructural..$^{54}$

13. Cabe comentar que el TC también dispone en este caso que el Ministerio de Educación le informe cada seis (o6) meses sobre el avance de las políticas públicas que diseñe e implemente a partir de esta sentencia, inscribiéndose así en la tendencia actual de algunos altos tribunales nacionales e internacionales de darle seguimiento a algunas de sus decisiones más importantes y de gran impacto social, en un intento parcial de "justicia dialógica" en la implementación progresiva de sus fallos. ${ }^{55}$

14. Por otro lado, la única sentencia del TC que se refiere directa e intencionalmente al derecho a la igualdad y no discriminación de las personas o pueblos indígenas, es la recaída en la STC oo889-2017-PA/TC. En este pronunciamiento, luego de ratificar que el derecho a la igualdad tiene una faz objetiva de principio y otra faz subjetiva de derecho y que no toda dis-

rurales de nuestro país y encontrarse en situación de pobreza extrema, no tienen acceso, en condiciones de igualdad, a la educación o a determinadas modalidades de educación básica regular, alternativa o especial... ... el Tribunal Constitucional, en tanto órgano de control de la Constitución, no debe pronunciarse solo cuando cada persona del ámbito rural y pobre interponga una demanda de amparo, si acaso ello ocurriese, pues dada la precariedad de sus recursos es poco probable que judicialice el respetivo reclamo en defensa de sus derechos, sino también se encuentra legitimado para pronunciarse mediante técnicas como aquella del estado de cosas inconstitucional." Sentencia del Tribunal Constitucional $\mathrm{N}^{\circ}$ 008-53-2015-PA, de 14 de marzo de 2017 , pp. 61, 65, 72 .

54 "Por consiguiente, atendiendo a lo expuesto en los parágrafos precedentes, en los cuadros estadísticos elaborados por el Ministerio de Educación antes citados y a que las personas de extrema pobreza del ámbito rural están expuestas a condiciones que fomentan su vulnerabilidad, el Tribunal Constitucional considera que debe declararse un estado de cosas inconstitucional en el caso de la disponibilidad y accesibilidad a la educación de tales personas de extrema pobreza en el ámbito rural, de modo tal que se ordene al Ministerio de Educación: a) diseñar, proponer y ejecutar un plan de acción que en un plazo máximo de cuatro años, que vencería el 28 de julio de 2021, año del bicentenario, pueda asegurar la disponibilidad y accesibilidad a la educación de niños, adolescentes y mayores de edad, de extrema pobreza del ámbito rural, empezando por los departamentos de Cajamarca, Amazonas, Ayacucho y Huancavelica... d) ordenar al Ministerio de Educación informe al Tribunal Constitucional, cada 6 meses, el avance de lo aquí dispuesto." Sentencia del Tribunal Constitucional No $008-53-2015-\mathrm{PA}$, de 14 de marzo de 2017, p. 75.

55 Gargarella (2014). 
tinción es inconstitucional per se, sostiene que, en determinadas circunstancias, para realizar el derecho a la igualdad sustancial el Estado tiene el deber de adoptar medidas positivas a favor de personas que hablan otra lengua distinta al castellano (en este caso, el quechua) con el fin de que, en los hechos, dicha lengua también sea usada como idioma oficial por parte de las autoridades estatales en dicha región; de lo contrario se estaría incurriendo en "una discriminación por indiferenciación".56

Llama la atención que estas decisiones jurisdiccionales del TC vinculadas -directa o indirectamente- al derecho a la igualdad y no discriminación de las personas y pueblos indígenas, no hayan incorporado en su razonamiento ni hayan hecho mención alguna al test de igualdad que el TC desarrolló desde el año 2005 a partir del "caso PROFA".57

$\mathrm{Al}$ respecto, consideramos, por un lado, que dado el desarrollo que el derecho a la igualdad y no discriminación ha tenido en los últimos años y, por otro lado, la discriminación estructural, indirecta e interseccional que suelen enfrentar las personas y pueblos indígenas, hoy en día el referido test de igualdad no es una herramienta completa para determinar la violación del derecho a la igualdad en estos casos. Tal como postularemos en el siguiente punto del presente artículo, a futuro el TC podría de-construir el test de igualdad desde una perspectiva estructural o contextual.

\section{Los retos de la jurisprudencia constitucional peruana en torno al derecho a la igualdad y no discriminación de los pueblos indígenas}

Ante el amplio desarrollo que ha tenido el principio/derecho de igualdad y no discriminación tanto a nivel doctrinal como jurisprudencial y frente a la situación histórica y estructural de exclusión y discriminación de las personas y pueblos indígenas documentada tanto por informes oficiales nacionales e internacionales,

56 “... se está produciendo una violación del derecho a la igualdad en su dimensión sustancial. Se está produciendo una discriminación por indiferenciación, puesto que el Estado viene tratando de la misma forma a quien tiene como lengua materna el castellano y quien no, cuando tiene el deber de adoptar medidas afirmativas o positivas para que este último no solo no se vea afectado en su derecho a usar su propio idioma ante cualquier autoridad a nivel nacional, sino también en su derecho a que la lengua predominante en una zona sea, junto al castellano, el idioma oficial de comunicación por parte del Estado. Tales medidas son las especificadas en la ley de lenguas y su reglamento, las cuales hasta la fecha no han sido suficientemente implementadas." Sentencia del Tribunal Constitucional No 0889-2017-PA, de 17 de abril de 2018, p. 23.

57 Sentencia del Tribunal Constitucional del Perú N 045-2004-PI, de 29 de octubre de 2005. 
los estándares, técnicas y principios de interpretación desarrollados a la fecha por el Tribunal Constitucional peruano en torno al derecho a la igualdad y no discriminación de los pueblos indígenas, resultan insuficientes.

Por ello, a continuación concluimos el presente artículo postulando algunas recomendaciones que el máximo intérprete de la Constitución podría considerar para seguir desarrollando el contenido constitucional del derecho a la igualdad y no discriminación de las personas y pueblos indígenas, tomando muy en cuenta que "la igualdad como no sometimiento obliga a reformular el rol de los tribunales y sus posibles respuestas cuando... afrontan demandas de personas pertenecientes a grupos sojuzgados que esperan del Estado una postura enérgica". ${ }^{58}$

a) La jurisprudencia constitucional debería incorporar en los casos de posible discriminación en contra de personas o pueblos indígenas, la variable histórica, estructural o contextual. Esto es mucho más importante en un país como el Perú, que cuenta con una gran diversidad étnica y cultural, que ha sido reconocida constitucionalmente como el derecho fundamental a la identidad étnica y cultural y que supone, entre otros aspectos, el deber del Estado de proteger tal pluralidad. ${ }^{59}$

b) Para ello, la jurisprudencia constitucional puede apoyarse en información estadística que ahora producen y actualizan diversas entidades oficiales como el Instituto nacional de estadística e informática (INEI), el Ministerio de Cultura, Ministerio de la mujer y poblaciones vulnerables, CEPAL, Banco Mundial, entre otros.

c) Lo anterior permitiría a la jurisprudencia constitucional determinar si un caso concreto es representativo -o no- de un problema estructural más grande que afecta no sólo a las partes de un proceso, sino a un sector o grupo social como, por ejemplo, niñas o mujeres indígenas o rurales, tal como ya hizo el TC en el caso ya comentado de "niñas rurales".

d) Si la jurisprudencia constitucional determina que un caso concreto es, además, representativo de un problema colectivo o social, entonces debería

58 SABA (2016), p. 81.

59 "Toda persona tiene derecho: A su identidad étnica y cultural. El Estado reconoce y protege la pluralidad étnica y cultural de la Nación." (artículo $2.19^{\circ}$ ). En similar sentido artículo $48^{\circ}$ (idiomas oficiales también las lenguas indígenas), artículo $88^{\circ}$ (derecho de propiedad colectiva de tierras de comunidades indígenas), artículo $89^{\circ}$ (reconocimiento personalidad jurídica y autonomía a comunidades indígenas) y artículo $149^{\circ}$ (reconocimiento de jurisdicción indígena). 
desarrollar y ordenar no sólo medidas de reparación sino también medidas correctivas o de no repetición, a través de acciones positivas o políticas públicas encaminadas explícitamente a favorecer -por un tiempo determinado- a cierto grupo de personas o pueblo indígena.

e) Ciertamente, lo anterior supondrá que el Tribunal Constitucional no limite ni culmine su actividad jurisdiccional con la dación de una sentencia, sino que en algunos casos emblemáticos en los que haya ordenado la implementación de acciones positivas o políticas públicas, extienda su actuación jurisdiccional a la supervisión ex post del cumplimiento de su sentencia.

f) Para ello, el Tribunal Constitucional podría hacer uso y desarrollar diversas herramientas como, por ejemplo, ordenar a las entidades públicas correspondientes que cada cierto tiempo informe al Tribunal sobre el avance en la implementación de las medidas o políticas públicas ordenadas, tal como ya ha hecho el TC en varios casos como el de "Las niñas rurales". Pero también puede desarrollar otros instrumentos como las audiencias y resoluciones de supervisión de cumplimiento de sentencias que la Corte interamericana ya lleva a cabo hace algunos años. ${ }^{60}$

g) En este sentido se pronunció precisamente la magistrada Marianella Ledesma cuando asumió la Presidencia del TC en enero del 2020, al ofrecer como uno de los lineamientos de su gestión la supervisión de sus sentencias a través de audiencias de seguimiento: "No es suficiente que el Tribunal expida sentencias para la tutela de derechos; es necesario verificar el cumplimiento de éstas. Por ello, ANUNCIO que acentuaremos la labor de la Comisión de seguimiento y cumplimiento de sentencias del Tribunal Constitucional... Resulta indispensable que estas sentencias se cumplan eficazmente y en todos sus alcances, para lo cual se establecerán Audiencias de seguimiento...." ${ }^{61}$

h) Ahora bien, si la jurisprudencia constitucional avanza en el desarrollo del derecho a la igualdad y no discriminación hacia un horizonte histórico, estructural o contextual, también avanzará hacia situaciones o realidades

60 “(...) desde hace tiempo tanto la Comisión como la Corte siguen el cumplimiento de sus respectivas decisiones por los Estados. Para ello utilizan diversas herramientas, como los informes anuales o, en el caso de la Corte, las audiencias o resoluciones de seguimiento de cumplimiento de una sentencia y, en el caso de la Comisión, las reuniones de trabajo (...)". Lovatón (2017), p. 107.

61 Ledesma (2020), p. 4. 
objetivas de discriminación de personas o pueblos indígenas, ante lo cual, también debería innovar en los estándares probatorios. Así, en algunos casos ya no sería necesario que el o los demandantes prueben una intención discriminatoria, sino que bastará con que prueben una situación o realidad objetiva de marginación, sometimiento o discriminación en comparación con otros sectores o grupos sociales. En otras palabras, la jurisprudencia constitucional también podría transitar hacia una noción de discriminación indirecta en algunos casos.

i) Asimismo, la jurisprudencia constitucional podría tomar en cuenta los estándares interamericanos ya desarrollados tanto por la Comisión como por la Corte interamericanas, para desarrollar el derecho a la igualdad y no discriminación desde una perspectiva interseccional y a favor de grupos sociales en condiciones de vulnerabilidad, como niñas o mujeres indígenas, indígenas en situación de pobreza o pobreza extrema, entre otros. Sin duda, ello potenciaría el impacto que las decisiones del TC podrían tener en la solución progresiva de la discriminación histórica, estructural y en ocasiones interseccional, que con frecuencia enfrentan las personas y pueblos indígenas en nuestro país.

j) Finalmente, esta posible y deseable evolución de la jurisprudencia constitucional hacia un contenido más acabado y moderno del derecho a la igualdad y no discriminación de las personas y pueblos indígenas, también podría invitar a un reexamen o reevaluación del actual test de igualdad que el TC ya ha establecido.

k) Lo que podríamos denominar como un nuevo "test de igualdad estructural" tendría como propósito identificar posibles situaciones de discriminación estructural e interseccional individual, pero sobre todo colectiva y la determinación de acciones positivas o políticas públicas. Para ello, este nuevo test podría ensamblarse no sólo tomando como referente el ya clásico test de igualdad, sino también los siguientes pilares argumentativos:

- Determinar si el caso sometido a su competencia, es representativo de una situación de discriminación estructural o interseccional, en perjuicio de grupos o sectores sociales en condiciones de vulnerabilidad. Para ello se apoyaría en información y estadísticas oficiales.

- Determinar qué fines constitucionales se realizarían con ciertas medidas positivas o políticas públicas que podrían ordenarse para enfrentar la situa- 
ción de discriminación estructural o interseccional previamente identificada. Este sería el sub-principio de adecuación.

- Determinar si hay -o no- otras medidas positivas o políticas públicas igualmente efectivas pero menos restrictivas de otros derechos fundamentales o bienes constitucionales. Este sería el sub-principio de necesidad. En este punto sería clave incorporar en la evaluación de la medida positiva o política pública sometida a test, si la misma es propia -o no- de una sociedad democrática, que es un estándar ya desarrollado por el sistema interamericano de derechos humanos.

- Finalmente, determinar si estas medidas positivas o políticas públicas afectan en forma desmedida otros derechos fundamentales o bienes constitucionales, comparando con la realización de los otros derechos fundamentales que tales medidas positivas o políticas públicas sometidas al test buscan favorecer; favorecimiento que debería ser intenso y no leve. Este sería el sub-principio de proporcionalidad strictu sensu. En este punto sería clave tomar en cuenta la temporalidad de la medida o política sometida al test; como se sabe, toda acción dirigida a favorecer a un grupo históricamente discriminado, en principio, debe ser temporal.

\section{Bibliografía citada}

Clérico, Laura y Aldao, Martín (2011): "Nuevas miradas de la igualdad en la jurisprudencia de la Corte Interamericana de Derechos Humanos: la igualdad como redistribución y como reconocimiento", en Lecciones y Ensayos ( $\mathrm{N}^{\circ} 89$ ), pp. 141-179.

Clavero, Bartolomé (n.d.). "Libre determinación y pie de igualdad de los pueblos indígenas", [fecha de consulta: 5 de febrero de 2020]. [Disponible en: https://archivos.juridicas.unam.mx/www/bjv/libros/5/2482/17.pdf]

Comisión Interamericana de Derechos Humanos (2008): Lineamientos para la elaboración de indicadores de progreso en materia de derechos económicos, sociales y culturales. OEA/Ser.L/V/II.132. Doc.14 - 19 de julio 2008 (Washington DC, Comisión Interamericana de Derechos Humanos).

Comisión Interamericana de Derechos Humanos (2014): Mujeres indígenas desaparecidas en Canadá. OEA/Ser.L/V/II. Doc. 30/14 21, de diciembre 2014 (Washington DC, Comisión Interamericana de Derechos Humanos). 
Comisión Interamericana de Derechos Humanos (2015a): Pueblos indígenas, comunidades afrodescendientes y recursos naturales: protección de derechos humanos en el contexto de actividades de extracción, explotación y desarrollo. OEA/Ser.L/V/II. Doc.47/15. 31 de diciembre 2015 (Washington DC, Comisión Interamericana de Derechos Humanos).

Comisión Interamericana de Derechos Humanos (2015b): Violencia contra Personas Lesbianas, Gay, Bisexuales, Trans e Intersex en América. OAS/Ser.L/V/ II.rev.2. Doc. 36. 12 de noviembre 2015 (Washington DC, Comisión Interamericana de Derechos Humanos).

Comisión Interamericana de Derechos Humanos (2015c): Situación de los derechos humanos en Guatemala: Diversidad, desigualdad y exclusión. OEA/ Ser.L/V/II. Doc. 3/15. 31 de diciembre 2015 (Washington DC, Comisión Interamericana de Derechos Humanos).

Comisión Interamericana de Derechos Humanos (2015d): Situación de derechos humanos en Honduras. OEA/Ser.L/V/II. Doc. 42/15. 31 de diciembre 2015 (Washington DC, Comisión Interamericana de Derechos Humanos).

Comisión Interamericana de Derechos Humanos (2017): Informe Pobreza y derechos humanos. OEA/Ser.L/V/II.164 (Washington DC, Comisión Interamericana de Derechos Humanos).

Comisión Interamericana de Derechos Humanos (2019a). "Compendio Igualdad y no discriminación estándares interamericanos”, [fecha de consulta: 6 de febrero de 2020]. [Disponible en: https://www.oas.org/es/cidh/informes/ pdfs/Compendio-IgualdadNoDiscriminacion.pdf]

Comisión Interamericana de Derechos Humanos (2019b). "Informe pueblos indígenas y tribales de la Panamazonia”, [fecha de consulta: 6 de febrero de 2020]. [Disponible en: http://www.oas.org/es/cidh/informes/pdfs/Panamazonia2019.pdf]

COMISIÓn NACIONAL CONTRA LA DISCRIMINACIÓN (2019). "Informe sobre la discriminación en medios de comunicación en el Perú, con especial énfasis en la discriminación étnico-racial", [fecha de consulta: 6 de febrero de 2020]. [Disponible en: https://observatorioderechoshumanos.minjus.gob.pe/wp-content/ uploads/2019/og/Informe-Tematico-I-2019_web.pdf]

Corte Interamericana de Derechos Humanos (2003). “Condición jurídica y derechos de los migrantes indocumentados. Opinión Consultiva OC-18/03 de 17 de septiembre de 2003. Serie A No. 18", [fecha de consulta: 6 de febrero de 
2020]. [Disponible en: http://www.corteidh.or.cr/docs/opiniones/seriea_18_ esp.pdf]

Corte Interamericana de Derechos Humanos (2016). “Titularidad de derechos de las personas jurídicas en el sistema interamericano de derechos humanos. Opinión consultiva OC-22/16 de 26 de febrero de 2016 solicitada por la República de Panamá", [fecha de consulta: 6 de febrero de 2020]. [Disponible en: http://www.corteidh.or.cr/docs/opiniones/seriea_22_esp.pdf]

Corte Interamericana de Derechos Humanos (2017). "Medio Ambiente y Derechos Humanos. Opinión consultiva OC-23/17 de 17 de noviembre de 2017 solicitada por la República de Colombia”, [fecha de consulta: 6 de febrero de 2020]. [Disponible en: http://www.corteidh.or.cr/docs/opiniones/seriea_23_ esp.pdf]

Defensoría del Pueblo (2019). "Situación de los derechos de las mujeres indígenas en el Perú. Informe No oo2-2019-DP/AMASPPI/PPI”, [fecha de consulta: 6 de febrero de 2020]. [Disponible en: https://www.defensoria.gob.pe/ wp-content/uploads/2019/12/Informe-de-adjuntia-oo2-2019-PPI-Digital.pdf]

Gargarella, Roberto (Comp.) (2014): Por una justicia dialógica, El Poder Judicial como promotor de la deliberación democrática (Buenos Aires, Siglo XXI Editores).

Ledesma, Marianella (Coord.) (2015). Justicia, derecho y sociedad, Debates interdisciplinarios para el análisis de la justicia en el Perú (Lima, Centro de estudios constitucionales (CEC) del Tribunal Constitucional).

Ledesma, Marianella (Coord.) (2017): Justicia e Interculturalidad, Análisis y pensamiento plural en América y Europa (Lima, Centro de estudios constitucionales (CEC) del Tribunal Constitucional).

Ledesma, Marianella (2020). "Speech", [fecha de consulta: 5 de febrero de 2020]. [Disponible en: https://tc.gob.pe/publicaciones/resumenes/2020/enero/discurso_03.01.2020.pdf].

Lovatón, David (2017). La gestación del Estado constitucional interamericano. (Lima, Pontificia Universidad Católica del Perú y Fundación para el debido proceso-DPLF).

Mensajes del Informe Final de la CVR: Victimas (2006). "[Video]”, [fecha de consulta: 5 de febrero de 2020]. [Disponible en: https://www.youtube.com/ watch?v=HE_Fu_x5FZ8\&t=12s] 
Ministerio de Cultura del Perú (n.d.). “Base de datos de pueblos indígenas u originarios”, [fecha de consulta: 5 de febrero de 2020]. [Disponible en: https:// bdpi.cultura.gob.pe/]

Ministerio de Cultura del Perú (n.d.). "Indicadores sociodemográficos de la Base de datos de pueblos indígenas u originarios", [fecha de consulta: 4 de febrero de 2020]. [Disponible en: https://bdpi.cultura.gob.pe/ indicadores-sociodemograficos]

Ministerio de Cultura del Perú (n.d.). "Situación y nivel de pobreza. (2019)", [fecha de consulta: 6 de febrero de 2020]. [Disponible en: https://bdpi.cultura. gob.pe/sites/default/files/archivos/paginas_internas/items/Situacion\%20y\%20 nivel\%2ode\%2opobreza\%2oenaho\%202018.pdf]

Organización de Naciones Unidas (1989). “Observación General № 18 del Comité de derechos humanos”, [fecha de consulta: 5 de febrero de 2020]. [Disponible en: https://www.acnur.org/fileadmin/Documentos/BDL/2001/1404. pdf]

Organización de Naciones Unidas Mujeres (2019). "Mejoramiento de la situación de la mujer y la niña en las zonas rurales: Informe del Secretario General", [fecha de consulta: 6 de febrero de 2020]. [Disponible en: https://www.unwomen.org/es/digital-library/ publications/2019/07/a-74-224-sg-report-women-and-girls-in-rural-areas]

Oficina en México del Alto Comisionado de las Naciones Unidas para LOS DERECHOS hUMANOS (2018). "Los derechos de los pueblos indígenas en México: una mirada desde los organismos del sistema de Naciones Unidas", [fecha de consulta: 5 de febrero de 2020]. [Disponible en: https://www.hchr. org.mx/images/doc_pub/PueblosIndgenas_UnaMirada_2017.pdf

NASH, Claudio y DAvid, Valeska (2010): "Igualdad y no discriminación en el sistema interamericano de derechos humanos", en NAsh, Claudio y MujicA, Ignacio. Derechos humanos y juicio justo (Lima, Red interamericana de formación en gobernabilidad y derechos humanos, Colegio de las Américas y Organización Interamericana) pp. 159-186.

Papa Francisco (2015): Carta Encíclica Ladauto Sí' - Sobre el cuidado de la casa común.

Pelletier, Paola (2014): "La "discriminación estructural" en la evolución jurisprudencial de la Corte interamericana de derechos humanos", en Instituto Interamericano de Derecho Humanos (IIDH), ( $\left.\mathrm{N}^{\circ} 60\right)$. 
Popolo, Fabiana del (ed.) (2017): Los pueblos indígenas en América (Abya Yala), Desafíos para la igualdad en la diversidad (Santiago de Chile, Comisión Económica para América Latina y el Caribe-CEPAL).

Rodríguez Garavito, César y Baquero Díaz, Carlos (2015): Reconocimiento con redistribución: El derecho y la justicia étnico-racial en América Latina (Bogotá, Centro de estudios de derecho, justicia y sociedad-DeJusticia).

SABA, Roberto (2016): Más allá de la igualdad formal ante la ley. ¿Qué les debe el Estado a los grupos desaventajados? (Buenos Aires, Siglo XXI Editores).

SALOMÉ, Liliana (2015): "La «discriminación múltiple». Formación del concepto y bases constitucionales para su aplicación en el Perú", en Pensamiento constitucional ( $\left.\mathrm{N}^{\circ} 20\right)$, pp. 311-334.

SALOMÉ, Liliana (2017). "El concepto "discriminación estructural” y su incorporación al Sistema interamericano de protección de los derechos humanos", [fecha de consulta: 6 de febrero de 2020]. [Disponible en: https://e-archivo.uc3m. es/bitstream/handle/10016/24956/TFM_MEADH_Liliana_Salome_2017. pdf? sequence $=1$ \&isAllowed $=y$ ]

SAntos, Boaventura de Sousa (2014): Derechos humanos, democracia y desarrollo. (Bogotá, Centro de estudios de derecho, justicia y sociedad-DeJusticia).

VArgas Llosa, Mario (2010). "Speech. Estocolomo, Suecia", [fecha de consulta: 5 de febrero de 2020]. [Disponible en: https://www.ersilias.com/ discurso-de-mario-vargas-llosa-nobel-literatura-2010/]

\section{Normas jurídicas citadas}

Convenio OIT No 169 (1989). Organización Internacional del Trabajo.

Declaración americana sobre los derechos de los pueblos indígenas, AG/RES. 2888 (XLVI-O/16). (2016). Organización de Estados Americanos.

Declaración de las Naciones Unidas sobre los derechos de los pueblos indígenas. (2007). Naciones Unidas.

\section{Jurisprudencia citada}

Caso Gonzales Lluy y otros vs. Ecuador (2015): Corte Interamericana de Derechos Humanos, 1 de septiembre de 2015. Serie $\mathrm{C} \mathrm{N}^{\circ} 298$.

Caso Trabajadores de la Hacienda Brasil Verde vs. Brasil (2016): Corte Interamericana de Derechos Humanos, 20 de octubre de 2016. Serie $\mathrm{C} \mathrm{N}^{\circ} 318$ 
Caso Paisana Jacinta (2019): Corte Superior de Justicia de Cusco, 22 de mayo de 2019.

Caso "Profa" (2005): Tribunal Constitucional del Perú (proceso de inconstitucionalidad), 29 de octubre de 2005. Expediente 045-2004-PI.

Caso Niñas Rurales (2017): Tribunal Constitucional del Perú (proceso de amparo), 14 de marzo de 2017. Expediente 0o8-53-2015-PA.

Caso Derecho a comunicarse en su propia lengua indígena (2018): Tribunal Constitucional del Perú (proceso de amparo), 17 de abril de 2018. Expediente o889-2017-PA.

Caso Gobierno Regional de Loreto y reconocimiento de pueblos indígenas (2018): Tribunal Constitucional del Perú (proceso de inconstitucionalidad), 20 de julio de 2018. Expediente ooo4-2018-PI.

Caso Gobierno Regional de Cajamarca y reconocimiento de pueblos indígenas (2019): Tribunal Constitucional del Perú (proceso de inconstitucionalidad), 22 de enero de 2019. Expediente o012-2017- PI. 